\title{
Butyrate production from dietary fibre and protection against large bowel cancer in a rat model
}

\author{
A McIntyre, P R Gibson, G P Young
}

\begin{abstract}
Butyrate slows the growth of cancer cells cultured in vitro. To determine the relevance of the fermentative production of butyrate in vivo, colonic butyrate concentrations were manipulated by feeding different dietary fibres and were related to tumour development in the rat dimethylhydrazine model of large bowel cancer. It has previously been shown that guar gum and oat bran, while highly fermentable, are associated with low butyrate levels in the distal colon, while wheat bran causes significantly higher concentrations. Diets containing these fibres (nominally $10 \% \quad w: w)$ were administered for 3 weeks before, for 10 weeks during, and for 20 weeks after dimethylhydrazine administration, after which animals were killed and examined for tumours. Significantly fewer tumours were seen in the rats fed wheat bran compared with those fed guar or oat bran, and the total tumour mass was lowest in rats fed wheat bran. Rats on a 'no added fibre diet' had an intermediate tumour mass. Regression analysis, performed regardless of dietary group, showed that the concentration in stools of butyrate but not of acetate or stool volume, correlated significantly (and negatively) with tumour mass. These findings indicate that fibre which is associated with high butyrate concentrations in the distal large bowel is protective against large bowel cancer, while soluble fibres that do not raise distal butyrate concentrations, are not protective. Thus, butyrate production in vivo does bear a significant relationship to suppression of tumour formation.

(Gut 1993; 34: 386-391)
\end{abstract}

Many epidemiological and experimental studies have suggested that dietary fibre can protect against the development of large bowel cancer. The mechanisms by which fibres achieve this protection remain speculative. However, it is known that ingestion of fibre has a number of effects on intestinal physiology and on the large bowel luminal environment, any of which might mediate the protective effect. Fibre increases the intestinal transit rate ${ }^{12}$ and bulk and so dilutes constituents, ${ }^{3}$ modifies the intestinal microflora and so might alter bile salt and carcinogen metabolism, ${ }^{+}$adsorbs carcinogens and mutagens, ${ }^{5}$ modifies faecal bile salt excretion, ${ }^{6}$ lowers the colonic $\mathrm{pH}$ and increases colonic and faecal short chain fatty acid (SCFA) concentrations. ${ }^{7}$ The relative importance of these effects is uncertain. Because fibre is heterogeneous, it is also probable that different types act by different mechanisms.

One property which varies between fibres is fermentability. Fibre is fermented by anaerobic bacteria in the large bowel producing energy, hydrogen, carbon dioxide, methane, lactate, and SCFAs - predominantly acetate, propionate, and butyrate. ${ }^{8}$ One product of fermentation, butyrate, is particularly interesting as it has been found to slow proliferation and promote expression of phenotypic markers of differentiation in the large bowel cancer cell line LIM $1215^{\circ}$ and a range of other such lines. ${ }^{10}$ Thus, one explanation for the variable effects of fibre on development of bowel cancer" relates to the variable fermentability of different fibres ${ }^{12}$ and in turn to subsequent variation in the amounts of butyrate to which developing neoplasms are exposed. Recent findings in our laboratory have indicated that highly fermentable fibre (for example, guar gum) does not ensure high levels of butyrate in the distal large bowel where tumours are most common. ${ }^{13}$ Thus, a study of the impact of fermentative production of butyrate from dietary fibres on tumour development should include an evaluation of butyrate concentrations in the luminal contents of different regions of the large bowel.

The aim of this study was to relate the effects of three types of dietary fibre on fermentative production of butyrate in the distal colon to their effects on tumour mass in a rat model of bowel cancer. Guar gum was chosen because of its known solubility and high fermentability in the rat, ${ }^{13-15}$ while wheat bran was selected because of its relatively low fermentability. ${ }^{13}{ }^{14}$ Oat bran was selected as the third fibre because of the topical interest of this product, its effects on cholesterol metabolism, and because it is generally considered to be well fermented. . $^{16-18}$ The effects of these fibres on the luminal environment, including $\mathrm{pH}$, SCFA concentrations, and bacterial metabolising enzymes, were related to tumour mass in individual rats by regression analysis.

\section{Methods}

PROTOCOL

Sixty four, week old, male Sprague-Dawley rats $(60-100 \mathrm{~g})$ were randomly divided into four groups of 15 and housed, three to a cage, in dropped-bottom wire cages to minimise coprophagy and completely prevent consumption of bedding, which was $2 \mathrm{~cm}$ below the wire bottom. Each of the four groups had free access to water and one of the four diets. Diets were made up from plain white wheat flour (Water Wheel Flour Mill, Bridge Water, Victoria, Australia), skimmed milk powder (Drouin Cooperative, Victoria), butter (Western Star Pty Ltd, Melbourne, Victoria) unprocessed wheat bran 
(38\% fibre by analysis by Purina Health Foods Co, Melbourne, Victoria), oat bran (26\% fibre by analysis by Anchor Foods Pty Ltd, Footscray, Victoria) and/or guar gum (Vitality Products Pty Ltd, Melbourne, Victoria). The diets were standardised so that protein, carbohydrate, and fat provided approximately $20 \%, 60 \%$, and $20 \%$ of the energy content respectively. A standard vitamin mix (Colborn Dawes, Australia Pty Ltd) and mineral mix as per the standard AIN-76 $\operatorname{diet}^{19}$ were added to the diets.

The 'basic' diet contained no added fibre (normally 5 or $10 \%$ pure cellulose in the AIN-76 diet); while the guar gum, oat bran, and wheat bran diets had sufficient fibre added to give a nominal $10 \%$ fibre (w:w), wheat flour was adjusted accordingly to keep the carbohydrate content constant. The actual fibre content (soluble and insoluble) of each diet was measured by the Australian Government Analytical Laboratories (Melbourne, Victoria, Australia) using the enzymatic method described by the Association of Official Analytical Chemists. ${ }^{20}$ Diets were extracted with water to allow determination of the 'soluble' and 'insoluble' fibre contents. Fibre contents, as a proportion of dry weight were as follows: basic (3.1\%-57\% soluble), guar gum $(12 \cdot 9 \%-85 \%$ soluble), oat bran $(11 \cdot 3 \%-51 \%)$, wheat bran $(11 \cdot 6 \%-24 \%)$. These differed from nominal amounts added because of the moisture content of the various constituents from which the diets were made. Complete analysis of the diets, and in vivo fermentability of the fibres, has previously been reported in detail. ${ }^{13} \mathrm{~A}$ nominal fibre content of $10 \%$ in the rat diets was chosen as this approximates a relatively high fibre intake in humans using calculations based on recommended energy intakes from the Department of Health and Social Security UK. ${ }^{21} \mathrm{~A}$ woman aged $18-54$ years requiring $9 \mathrm{MJ}$ of energy per day would consume approximately $50 \mathrm{~g}$ protein, $300 \mathrm{~g}$ carbohydrate, and $70 \mathrm{~g}$ fat. A $10 \%$ fibre content would correspond to approximately $40 \mathrm{~g}$ fibre per day, which is a little above the measured range of 8-32 $\mathrm{g}$ per day in a British population. ${ }^{21}$

Rats were injected subcutaneously with 30 $\mu \mathrm{g} / \mathrm{g}$ body weight of 1,2-dimethylhydrazine (Sigma Chemical Co, St Louis, MO, USA) once a week for 10 weeks, beginning 3 weeks after starting the diet. The protocol was approved by the Campus Animal Ethics Committee and the Board of Medical Research of The Royal Melbourne Hospital.

TABLE I Body weight, caecal and faecal weight, and $p H$ of caecal contents and faeces of rats on the four diets (values mean (SEM))

\begin{tabular}{lllll}
\hline & Diet & & & \\
\cline { 2 - 5 } & Basic & Guar & Oat bran & Wheat bran \\
\hline Body weight at sacrifice $(\mathrm{g})$ & $527(11)$ & $509(14)$ & $523(17)$ & $532(18)$ \\
Caecal weight at sacrifice $(\mathrm{g})^{\star}$ & $1 \cdot 09(0 \cdot 11)$ & $1 \cdot 52(0 \cdot 09)$ & $1 \cdot 12(0 \cdot 06)$ & $1 \cdot 27(0 \cdot 15)$ \\
24 hour faecal weight before sacrifice $(\mathrm{g}) \dagger$ & $1.95(0 \cdot 10)$ & $4 \cdot 52(0 \cdot 44)$ & $2 \cdot 03(0 \cdot 19)$ & $4 \cdot 27(0 \cdot 19)$ \\
pH of caecal contentsł & $6 \cdot 2(0 \cdot 2)$ & $6 \cdot 0(0 \cdot 2)$ & $6 \cdot 1(0 \cdot 1)$ & $6 \cdot 1(0 \cdot 2)$ \\
pH of faeces before sacrifice $\$$ & $7 \cdot 0(0 \cdot 1)$ & $6 \cdot 6(0 \cdot 2)$ & $6 \cdot 6(0 \cdot 2)$ & $6 \cdot 2(0 \cdot 2)$ \\
\hline
\end{tabular}

$\star$ Diet significantly influenced caecal weight $(p=0 \cdot 02$, analysis of variance). Only for guar was the value significantly higher than basic $(p=0 \cdot 016)$. $†$ Diet significantly affected 24 hour faecal weigh $(\mathrm{p}=0.0000001$, analysis of variance). Significant intergroup comparisons were: basic diet v guar or wheat bran, $p<0.00001$; oat bran $\mathrm{v}$ wheat bran or guar, $p<0.0001$. $\neq$ Diet did not significantly affect caecal $p H$. Diet significantly affected faecal $p H(p=0.008$, analysis of variance). Significant intergroup comparisons were: wheat bran $\mathrm{v}$ basic diet, $p=0 \cdot 0015$; Other comparisons, $p>0 \cdot 1$
FAECAL SAMPLES

Freshly passed faeces were collected from each rat before sacrifice and the $\mathrm{pH}$ measured within 1 minute of stool collection using a glass body combination, protein resisting electrode (Activon RU341) inserted into the stool. The recording tip was $4.5 \mathrm{~mm}$ in largest dimension and was totally embedded in the stool being measured. The coefficient of variation for 10 measures taken from a single stool was $4 \cdot 0 \%$. Another stool sample of known weight was immediately covered with ice cold saline of known volume in a screw capped vial, which was filled and tightly closed to avoid formation of any dead space. This was frozen at $-20^{\circ} \mathrm{C}$ for later SCFA and enzyme analysis. SCFAs remained stable under the conditions of storage. Average faecal wet weight/rat/24 hours was measured for each diet by collecting all faecal matter, separate from urine, from cages over three serial 24 hour periods in the week before sacrifice. Each cage contained two or three rats.

\section{CAECAL CONTENTS}

Twenty weeks after the last dimethylhydrazine injection, rats were killed by carbon dioxide narcosis, the peritoneal cavity was rapidly opened, and the caecum was removed. The $\mathrm{pH}$ of its contents was measured as above and a sample of contents stored as for faeces.

\section{TUMOURS}

The colon was removed, flushed with ice cold saline, and cut open. The presence or absence of tumours was noted as was their relative position - that is, either in the proximal or distal colon. The tumour size was measured in two dimensions (at an angle of $\left.90^{\circ}\right)$ and a tumour size index $\left(\mathrm{mm}^{2}\right)$ as a measure of mass was calculated for each rat by multiplying these. Eleven rats either died or were killed before the end of the 30 week experimental period. All of these rats had bowel tumours and the most common cause of death was bowel obstruction by tumour. Of these rats, four were on the basic diet, one on guar, five on oat bran, and one on wheat bran. With the exception of four rats (one on basic diet, two oat bran, one wheat bran), data on tumour incidence and size was included in the analyses, but data were not available for measures of caecal contents. Macroscopic tumours were fixed in $10 \%$ buffered formalin, embedded in paraffin sections. $(3-5 \mu \mathrm{m})$ were cut and stained with haematoxylin and eosin. Tumours were classified as benign or malignant according to whether the basement membrane had been invaded ${ }^{22}$; only malignant tumours were considered for the analyses.

SCFA

Details of our application of the previously described method $^{23}$ have recently been reported. ${ }^{13}$ Briefly, an aliquot of thawed and vortex mixed sample $(600 \mu \mathrm{l}$ for faeces, $300 \mu \mathrm{l}$ for caecal contents) was added to $300 \mu$ lether, 60 ul $50 \% \mathrm{H}_{2} \mathrm{SO}_{4}$, and $0.35 \mathrm{~g} \mathrm{NaCl}$ in a capped tube. After gentle mixing for 2 minutes and 
Figure 1: The effect of diet on concentrations of the three principal short chain fatty acids, acetate $(A)$, propionate $(B)$ and butyrate $(C)$, in caecal contents. Values, mean (SEM). (See Table II for interdiet comparisons).
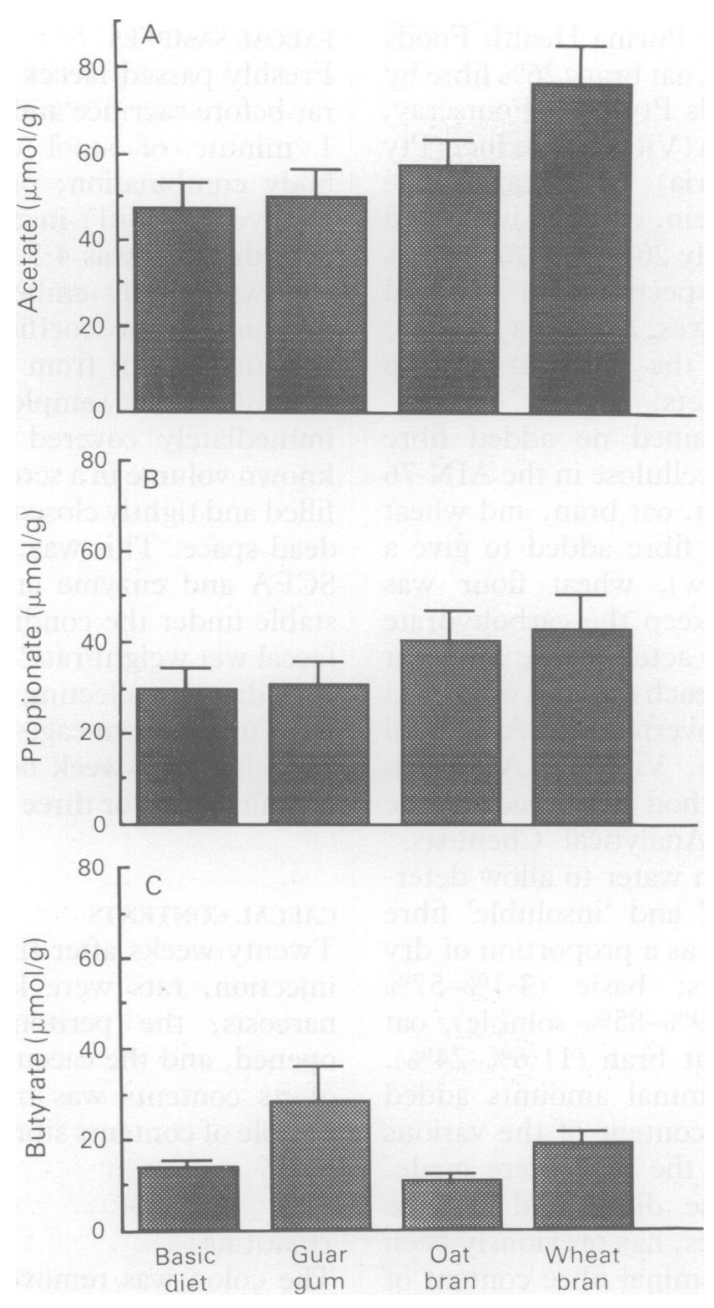

centrifugation at $14000 \mathrm{rpm}$ for 5 minutes, a $5 \mu \mathrm{l}$ aliquot of the top ether phase was injected into a gas chromatograph (Perkin-Elmer 3920) (column temperature $170^{\circ} \mathrm{C}$ ). A standard SCFA mixture containing acetate, propionate, isobutyrate, and butyrate was used for calculation of the SCFA concentrations and the results are presented as $\mu \mathrm{mol} / \mathrm{g}$ of wet faeces or wet caecal content. The intraexperimental coefficient of variation of a standard sample repeatedly measured $(n=10)$ for butyrate was $9 \%$. Extraction of butyrate into the ether phase was $>95 \%$.

\section{STATISTICAL ANALYSES}

All comparisons were made using either a $t$ test (unpaired, pooled estimate of variance) (Microstat release $4 \cdot 1$ computer program, Ecosoft Inc, Indianopolis USA), or analysis of variance when multiple variables were being evaluated (Complete Statistical Systems, CSS, StatSoft, 1988); in the analyses of variance, significance of intergroup comparisons were made using the 'planned comparisons option' of CSS. Tumour numbers were not normally distributed and were compared using the Wilcoxon rank sum test (Microstat). Tumour size indices were normally distributed. The criterion taken for significance was $\mathrm{p}<0.05$. Stepwise multiple region regression was performed using Microstat.

Preliminary studies had indicated that the size chosen for the groups had sufficient power to detect the differences in tumour burden that were observed. Furthermore, examination of the relationship between butyrate (and other measures) and tumour development by regression analysis used data from each animal regardless of dietary group - thus, we were able to avoid use of large numbers of animals.

\section{Results}

\section{RAT BODY WEIGHT}

All dietary groups gained weight at similar rates over the 30 week experimental period (Table I). By analysis of variance, there was no significant effect of diet on body weight.

\section{FAECAL CHARACTERISTICS}

The guar and wheat bran diets produced substantially and significantly higher faecal outputs than the basic and oat bran diets just before sacrifice (Table I). With oat bran and basic diets, stools were firm, with wheat bran stools were soft, while with guar gum, stools were semiformed.

\section{PH}

Table I shows caecal and faecal $\mathrm{pH}$ values for each of the four diets. Analysis of variance showed that diet did affect faecal $\mathrm{pH}$; this was solely attributable to differences (that is, lower $\mathrm{pH}$ ) in wheat bran compared with all other diets. The $\mathrm{pH}$ of the caecal contents did not differ significantly between diets.

SCFA

\section{Caecal contents}

The effects of diet on the concentrations of individual caecal SCFAs are shown in Figure 1A-C and the statistical analyses in Table II. By analysis of variance, diet significantly affected acetate $(p=0.0004)$, propionate $(p=0.019)$, and butyrate $(p=0.0017)$ concentrations; while concentrations tended to be higher in fibre fed animals, this was not invariably so.

\section{Faeces}

The effects of diet on concentrations of individual

TABLE II Table of $p$ values for interdiet comparisons of caecal SCFAs

\begin{tabular}{|c|c|c|c|}
\hline Diet & Guar & Oat & Wheat \\
\hline \multicolumn{4}{|l|}{ Acetate: } \\
\hline Basic & $0 \cdot 776$ & 0.934 & 0.018 \\
\hline Guar & - & $0 \cdot 760$ & 0.052 \\
\hline Oat & - & - & 0.015 \\
\hline \multicolumn{4}{|c|}{ Analysis of variance: diet, $\mathrm{p}=0.043(\mathrm{SS}=48668, \mathrm{DF}=3, \mathrm{~F}=2.942$} \\
\hline \multicolumn{4}{|c|}{ Propionate: } \\
\hline Basic & 0.597 & 0.494 & $0 \cdot 232$ \\
\hline Guar & - & $0 \cdot 828$ & 0.475 \\
\hline Oat & - & - & 0.612 \\
\hline \multicolumn{4}{|c|}{ Analysis of variance: diet, $p=0.690(S S=674, D F=3, F=0.499)$} \\
\hline \multicolumn{4}{|c|}{ Butyrate: } \\
\hline Basic & $0 \cdot 066$ & 0.680 & 0.612 \\
\hline Guar & - & 0.022 & $0 \cdot 178$ \\
\hline Oat & - & - & $0 \cdot 34+$ \\
\hline \multicolumn{4}{|c|}{ Analysis of variance: diet, $\mathrm{p}=0 \cdot 110(\mathrm{SS}=1544, \mathrm{DF}=3, \mathrm{~F}=2 \cdot 132$} \\
\hline
\end{tabular}


Figure 2: The effect of diet on concentrations of the three principal short chain fatty acids, acetate $(A)$, propionate $(B)$ and butyrate mean (SEM). (See Table III for interdiet comparisons). $(C)$, in fresh faeces. Values,

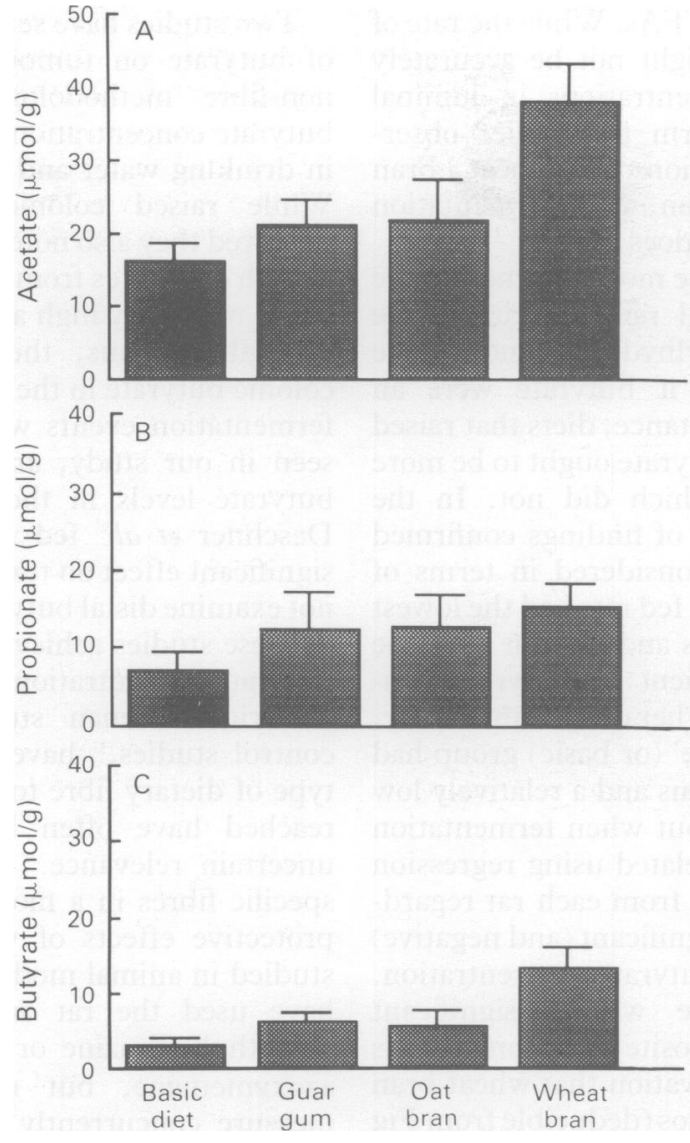

faecal SCFAs are shown in Figure 2A-C and the statistical analyses in Table III. Only wheat bran caused an increase in individual faecal SCFA concentrations compared with all other diets. Diet significantly affected concentrations of acetate $(p=0.00001)$, propionate $(p=0.010)$, and butyrate $(p=0 \cdot 00005)$. As faecal SCFA concentrations reflect those in the distal colon,,$^{13}$ this means that wheat bran maintained relatively high butyrate values along the length of the colon compared with other diets.

TABLE III Table of $p$ values for interdiet comparisons of faecal SCFAs

\begin{tabular}{|c|c|c|c|}
\hline Diet & Guar & Oat & Wheat \\
\hline \multicolumn{4}{|l|}{ Acetate: } \\
\hline Basic & $0 \cdot 370$ & $0 \cdot 340$ & 0.005 \\
\hline Guar & - & $0 \cdot 90$ & 0.045 \\
\hline Oat & - & & 0.041 \\
\hline \multicolumn{4}{|c|}{ Analysis of variance: diet, $\mathrm{p}=0.035(\mathrm{SS}=1942, \mathrm{DF}=3, \mathrm{~F}=3 \cdot 151$} \\
\hline \multicolumn{4}{|c|}{ Propionate: } \\
\hline Basic & $0 \cdot 808$ & 0.069 & 0.050 \\
\hline Guar & - & 0.38 & 0.026 \\
\hline Oat & - & - & 0.90 \\
\hline \multicolumn{4}{|c|}{ Analysis of variance: diet, $\mathrm{p}=0.047(\mathrm{SS}=772, \mathrm{DF}=3, \mathrm{~F}=2 \cdot 880)$} \\
\hline \multicolumn{4}{|c|}{ Butyrate: } \\
\hline Basic & $0 \cdot 760$ & $0 \cdot 205$ & $0 \cdot 017$ \\
\hline Guar & - & $0 \cdot 357$ & $0 \cdot 042$ \\
\hline Oat & - & - & $0 \cdot 022$ \\
\hline \multicolumn{4}{|c|}{ Analysis of variance: diet, $\mathrm{p}=0.046(\mathrm{SS}=832, \mathrm{DF}=3, \mathrm{~F}=2.459)$} \\
\hline
\end{tabular}

TABLE IV Effects of diets on tumour development

\begin{tabular}{|c|c|c|c|c|c|}
\hline Diet & No & $\begin{array}{l}\text { No of tumours per rat } \\
\text { (median interquartile } \\
\text { range) }\end{array}$ & $p^{\star}$ & $\begin{array}{l}\text { Tumour size index } \\
(\text { mean }(S E M))\end{array}$ & $p^{\prime \prime}$ \\
\hline Basic & 13 & $3(2-4)$ & $0 \cdot 24$ & $0.47\left(0 \cdot 15^{\star}\right)$ & $0 \cdot 139$ \\
\hline Guar & 14 & $4 \cdot 5(2-6)$ & 0.036 & $0.89(0.44)$ & $0 \cdot 19$ \\
\hline Oat bran & 12 & $3 \cdot 5(3-6)$ & 0.05 & $0.64(0.16)$ & $0 \cdot 22$ \\
\hline Wheat bran & 13 & $3(2-3 \cdot 75)$ & - & $0.27(0.06)$ & - \\
\hline
\end{tabular}

^ From comparison with wheat bran diet (using Wilcoxon rank sum test for tumour number and $t$ tes on log transformed data for tumour size index).
TUMOUR INCIDENCE

Rats fed the wheat bran diet had significantly fewer malignant tumours than those fed oat bran or guar gum (Table IV). All rats developed at least one large bowel tumour. The proportions of tumours found in the proximal colon were as follows: basic diet $-35 \%$, guar $-31 \%$, oat bran $33 \%$, and wheat bran $-36 \%$. Tumour size indices (a measure of total tumour mass) for the four diets are also shown in Table IV. The relative differences between diets were as for the tumour numbers, although none of the differences reached significance. Rats on the basic diet had an intermediate tumour burden when comparing either parameter of tumour development with that in any of the other diets (Table IV).

\section{RELATIONSHIP BETWEEN TUMOUR DEVELOPMENT} AND LUMINAL EVENTS

Univariate analysis and stepwise multiple regression were used to determine the relationship between the tumour size index (as the dependent variable) and luminal parameters of fermentation. In the univariate analysis, there was a significant negative correlation between butyrate and tumour size index (Table V); no other relationships were significant. In other words, the higher the butyrate concentration the lower the tumour mass. The regression model, which uses data for each rat as a single set and so relates measured parameters to tumour mass regardless of experimental group and hence diet (Table V), showed there to be two independent predictors of the index: butyrate having a negative relationship $(p=0.017)$ and propionate having a positive relationship $(p=0.03)$. The regression model accounted for $32 \%$ of the variance, in other words, these parameters of fermentation were not the sole determinants of tumour mass.

The butyrate concentrations did not show a significant correlation with $\mathrm{pH}$ or propionate concentrations. No significant relationships were seen between caecal parameters and tumour size index (data not shown).

\section{Discussion}

This study confirms the complexity of the effects of fermentable fibre on the luminal environment. Each fibre had different effects on stool bulk and consistency, $\mathrm{pH}$, and absolute and

TABLE V Multiple regression analysis of luminal parameters and tumour burden (tumour size index)

\begin{tabular}{|c|c|c|}
\hline Univariate analysis & $r^{\star}$ & $p$ \\
\hline \multicolumn{3}{|l|}{ Luminal variable: } \\
\hline Butyrate & -0.411 & 0.01 \\
\hline $\mathrm{pH}$ & $0 \cdot 240$ & $>0.5$ \\
\hline Propionate & 0.218 & $>0 \cdot 25$ \\
\hline Acetate & 0.033 & $>0 \cdot 8$ \\
\hline \multicolumn{3}{|l|}{ Multivariate analysis } \\
\hline \multicolumn{3}{|c|}{$\begin{array}{l}\text { Best model: } \\
\text { Best }\end{array}$} \\
\hline \multicolumn{3}{|c|}{$\begin{array}{l}\text { Tumour size index }=-2 \cdot 42-0 \cdot 013[\text { butyrate }]+ \\
0.016[\text { propionate }]+0 \cdot 209(\mathrm{pH})\end{array}$} \\
\hline \multicolumn{3}{|c|}{$r^{2}=0.316$, multiple $r=0.560, F$ ratio $=4.42, p=0.011$} \\
\hline \multicolumn{3}{|c|}{ Regression coefficients (SEM): } \\
\hline Butyrate & $-0.013(0.005)$ & $\mathrm{p}=0.017$ \\
\hline Propionate & $0.016(0.007)$ & $\mathrm{p}=0.030$ \\
\hline $\mathrm{pH}$ & $0.209(0.125)$ & $\mathrm{p}=0 \cdot 106$ \\
\hline
\end{tabular}

^Versus tumour size index. 
relative amounts of the SCFAs. While the rate of production of SCFAs might not be accurately reflected in SCFA concentrations in luminal contents, the data confirm the earlier observation $^{13}$ that fermentation of wheat bran continues in the distal colon, while fermentation of oat bran and guar gum does not.

Cancers are known to be more common in the distal large bowel ${ }^{2+25}$ and rarely occur in the caecum in the rat dimethylhydrazine model. We therefore reasoned that if butyrate were an important protective substance, diets that raised distal colonic or faecal butyrate ought to be more protective than those which did not. In the present study, two types of findings confirmed this. If the results are considered in terms of dietary group, wheat bran fed rats had the lowest tumour number and mass and did not have the falling caeco-faecal gradient in butyrate concentration seen with the other diets. Admittedly, rats in the 'no added fibre' (or basic) group had low butyrate concentrations and a relatively low tumour occurence rate, but when fermentation and tumour mass were related using regression analysis (which uses data from each rat regardless of diet) there was a significant (and negative) relationship with the butyrate concentration. Interestingly, propionate was a significant covariate - but in the opposite direction. This is consistent with the observation that wheat bran gave the highest molar ratios (deducible from Fig 2) for faecal butyrate - that is butyrate rose but propionate fell. Combining these observations with the evidence for a direct suppressing action of butyrate on colon cancer cell proliferation in vitro, ${ }^{90}$ it seems likely that butyrate itself suppresses tumour growth rather than some other undefined phenomenon associated with fermentative production of butyrate.

Fibres vary in their fermentability. While fibres in the diet are not chemically pure - for example, wheat bran consists of cellulose, hemicellulose, and lignin $\mathrm{s}^{26}$ - dietary fibres can be broadly classified according to their fermentability. Fibres in the highly fermentable group include guar gum (almost pure galactomannan) and pectin; these are soluble fibres that are well fermented in the rat intestine. ${ }^{14} 17$ Oat bran is considered to be well fermented in the rat; it is fairly rich in beta-glucan and poor in cellulose and lignin and has a poor bulking effect in the rat compared with poorly fermented fibres such as wheat bran. ${ }^{17827}$ The slowly fermentable group includes most wheat brans and the poorly fermentable group includes the purified celluloses (especially of wood origin) and lignin. ${ }^{1+}$

Butyrate is an important energy source for normal colonocytes ${ }^{28}$ as it is metabolised in preference to glucose and other substrates. It is of particular interest as it brings about a concentration-dependent slowing of the rate of cancer cell proliferation in vitro, ${ }^{10}$ at concentrations consistent with those encountered in the colon. Furthermore, it promotes in vitro expression of a differentiated phenotype in these cells. Alkaline phosphatase and dipeptidylpeptidase-IV, both markers of colonocyte differentiation, are increased during culture of LIM215 cells in the presence of butyrate. ${ }^{9}$ This differentiative effect might be a key protective mechanism.
Two studies have set out to examine the effect of butyrate on tumour development ${ }^{2930}$ using non-fibre methodologies to change colonic butyrate concentrations. Freeman ${ }^{29}$ fed butyrate in drinking water and saw no protective effect. While raised colonic butyrate levels were observed they also noted that colonic isobutyrate (which originates from amino acid fermentation) levels were very high and that ileal butyrate was negligible. Thus, the mechanism for raised colonic butyrate in their study was not clear, the fermentation events were different from those seen in our study, and they did not examine butyrate levels in the distal colon or faeces. Deschner $e t a l^{30}$ fed tributyrin - this had no significant effect on tumourigenesis but they did not examine distal butyrate levels either. Neither of these studies achieved the high distal colonic butyrate concentrations seen in our study.

Various human studies, particularly casecontrol studies, ${ }^{31}$ have attempted to relate the type of dietary fibre to cancer. The conclusions reached have often been conflicting and of uncertain relevance. ${ }^{32}$ In attempts to evaluate specific fibres in a more definitive fashion, the protective effects of various fibres have been studied in animal models. Most of these studies have used the rat and the carcinogen, 1,2 demethylhydrazine or its metabolic equivalent azoxymethane, but none has attempted to measure concurrently variables related to fermentation in the distal luminal environment in an attempt to explain why certain fibres are protective. Most of these studies have been summarised in two reviews." 18 What has been apparent is that highly fermentable fibres are less protective than less fermentable fibres. Our study confirms this generalisation and suggests a mechanism responsible for the effect, namely that less well fermented fibres result in coninued production of butyrate along the length of the large bowel. Rapidly fermented fibres could be completely broken down, leaving no substrate for fermentation in the distal colon. Alternatively, the more rapid transit of wheat bran compared with oat bran in the rat colon ${ }^{1618}$ might explain the difference in luminal butyrate levels.

The results in the animal model seem likely to be relevant to humans. There are parallels in the effect of dietary fibre; for instance, wheat bran when consumed throughout the initiation and promotion phases suppresses 1,2-dimethylhydrazine induced tumourigenesis and suppresses adenoma recurrence when given to patients with familial adenomatous polyposis. ${ }^{33}$ Also, the generalisation that insoluble grain fibre is more protective than soluble fibre in the rat model is confirmed by a detailed case-control study in humans where fibre type was carefully documented. ${ }^{3+}$ As pointed out in the methods section, the amount of fibre fed to the rats approximates the upper level of consumption in a British population.

Of the other luminal variables considered, neither $\mathrm{pH}$, acetate, faecal bulk, nor consistency seemed related to risk of developing tumours. Guar and wheat bran produced the largest stools, yet tumour frequency and bulk were quite different for the two fibres. This argues against 
fibre having a protective role simply by dilution of luminal carcinogens, although the present study does not take into account the differences in faecal water content encountered with these fibres. ${ }^{17}$

This study shows that a dietary fibre which maintains butyrate concentrations along the large bowel can reduce tumour mass. The presence of fermentable fibre in the distal colon and the resultant production of butyrate in that region seems of great significance than the production of other SCFAs, $\mathrm{pH}$, stool bulk, or stool consistency. Butyrate has the potential to modulate gene expression directly, ${ }^{35}$ and its production at the site of tumour formation may be a significant protective mechanism for certain dietary fibres.

This work has been supported by the Anti-Cancer Council of Victoria and the National Health and Medical Research Council of Australia. We wish to thank Pamela Lukaszewski for secretarial assistance.

Part published in abstract form; Gastroenterology 1991; 100: A411.

1 Burkitt DP. Epidemiology of cancer of the colon and rectum Cancer 1971; 28: 3-13.

2 Cummings $\mathrm{JH}$. Constipation, dietary fibre and the control of large bowel function. Postgrad Med f 1984; 60: 811-9.

3 Fleming SE, Marthinsen D, Kuhnlein H. Colonic function and fermentation in men consuming high fiber diets. $F$ Nutr and fermentation in

4 Jacobs LR. Relationship between dietary fibre and cancer: metabolic, physiologic and cellular mechanisms. Proc Soc metabolic, physiologic and cellular

5 Smith-Barbaro P, Hanson D, Reddy BS. Carcinogen binding to various types of dietary fiber. 7 Natl Cancer Inst. 1981;67 495-7.

6 Reddy BS, Watanabe K, Sheinfil A. Effects of dietary whea bran, alfalfa, pectin and carrageenan on plasma cholestero and fecal bile acid and neutral sterol in rats. $\mathcal{F}$ Nutr 1980 110: $1247-54$

7 Fleming SE, Fitch MD, Chansler MW. High-fiber diets: influence on characteristics of cecal digesta including shortchain fatty acid concentrations and $\mathrm{pH}$. Am 7 Clin Nutr 1989; 50: $93-9$.

8 Cummings JH. Short chain fatty acids in the human colon. Gut 1981; 22: 763-9.

9 Whitehead RH, Young GP, Bhathal PS. Effects of short chain fatty acids on a new human colon carcinoma cell line (LIM fatty acids on a new human color

$10 \mathrm{Kim}$ YS, Tsao D, Siddiqui B. Effects of sodium butyrate and dimethylsulfoxide on biochemical properties of huma colon cancer cells. Cancer 1980; 45: 1185-92.

11 Cameron IL, Ord Va, Hunter KE, Heitman DW. Colon carcinogenesis: modulation of progression. In: Moyer MP GH Poste, eds. Colon cancer cells. New York: Academic Press, 1990: 63-84.

12 Mcburney MI, Thompson LU. Effect of human faecal inoculum on in vitro fermentation variables. $\mathrm{Br} \mathcal{F}$ Nutr 1987 58: $233-3$.
13 Mcintyre A, Young GP, Taranto T, Gibson PR, Ward P. Different fibers have different regional effects on lumina contents of rat colon. Gastroenterology 1991; 101: 1274-81.

14 Nyman M, Asp N-G. Fermentation of dietary fibre components in the rat intestinal tract. Br 7 Nutr 1982; 47 : 357.

15 Tinker LF, Schneeman BO. The effect of guar gum or wheat bran on the disappearance of :C-labelled starch from rat gastrointestinal tract. 7 Nutr 1989; 119: 403-8.

16 Storer GB, Trimble RP, Illman RJ. Effects of dietary oat bran and diabetes on plasma and cecal volatile fatty acids in the and diabetes on plasma and

17 Jacobs LR, Lupton JR. Relationship between colonic luminal $\mathrm{pH}$, cell proliferation, and colon carcinogenesis in 1,2dimethylhydrazine treated rats fed high fiber diets. Cancer Res 1986; 46: 1727-34

18 Lupton JR, Meacher MM. Radiographic analysis of the effect of dietary fibers on rat colonic transit time. Am $\mathcal{F}$ Physio 1988; 225: G633-9.

19 Report of the American Institute of Nutrition Ad Hoc Committee on Standards for Nutritional Studies. 7 Nutr 1977; 107: 1340-8.

20 Association of Official Analytical Chemists (USA). Official methods of analysis 15th ed. 1990. Method 985.29.

21 Lentner C. Geigy Scientific Tables. Vol 1. Units of measurement, body fluids, composition of the body, nutrition. Basle: CibaGeigy Limited, 1981: 234-5.

22 Ward JM. Morphogenesis of chemically induced neoplasms of the colon and small intestine in rats. Lab Invest 1974; 30 $505-13$.

23 Whitehead JS, Kim YS, Prizont R. A simple quantitative method to determine short chain fatty acid levels in biological fluids. Clin Chim Acta 1976; 72: 315-8.

24 Schottenfeld D, Haas JF. Epidemiology of colon cancer. In Lipin M, Good RA, eds. Gastrointestinal tract cancer. New York: Plenum Publishing, $1978 ; 207-40$

25 Freeman HJ, Spiller GA, Kim YS. A double-blind study on the effect of purified cellulose dietary fiber on 1,2dimethylhydrazine-induced rat colonic neoplasia. Cancer Res 1978; 38: 2912-7.

26 Kay RM, Strasberg SM. Origin, chemistry, physiological effects and clinical importance of dietary fibres. Clin Invest Med 1978; 11: 9-24.

27 Jacob LR. Effects of dietary fiber on mucosal growth and cel proliferation in the small intestine of the rat: a comparison of oat bran, pectin and guar with total fiber deprivation. $A m \mathcal{F}$ Clin Nutr 1983; 37: 954-60.

28 Roediger WE. Utilization of nutrients by isolated epithelia cells of the rat colon. Gastroenterology 1982 82: 424-9.

29 Freeman HJ. Effects of differing concentrations of sodium butyrate on 1,2-dimethylhydrazine induced rat intestinal neoplasia. Gastroenterology 1986; 91 : 596-602

30 Deschner EE, Ruperto JF. Lupton JR, Newmark HL. Dietary butyrate (tributyrin) does not enhance AOMinduced colon tumorigenesis Cancer Lett 1990; 52:79-82.

31 Zaridze DG. Environmental etiology of large bowel cancer. $f$ Natl Cancer Inst 1983; 70: 389-99.

32 Wargovich MJ, Baer AR, Hu PJ, Sumiyoshi H. Dietary factors and colorectal cancer. Gastroenterol Clin North $\mathrm{Am}$ 1988; 17: 727-45.

33 DeCosse JJ, Miller HH, Lesser ML. Effect of wheat fibre and vitamins $\mathrm{C}$ and $\mathrm{E}$ on rectal polyps in patients with familia adenomatous polyposis. F Natl Cancer Inst 1989; 81: 1290-7.

34 Freudenheim JL, Graham S, Horvath PJ, Marshall JR, Haughey BP, Wilkinson G. Risks associated with source of fibre and fibre components in cancer of colon and rectum. Cancer Res 1990; 50: 3295-300.

35 Candido EP, Reeves R, Davies JR. Sodium butyrate inhibits histone deacetylation in cultured cells. Cell 1978; 14: 10513 . 